\title{
A comparative study of water-immiscible organic solvents in the production of furfural from xylose and birch
}

\author{
hydrolysate
}

Gerardo Gómez Millán ${ }^{\star[a, c]}$, Sanna Hellsten ${ }^{[a]}$, Alistair W. T. King ${ }^{[d]}$, Juha-Pekka

Pokki $^{[b]}$, Jordi Llorca ${ }^{[c]}$, Herbert Sixta ${ }^{[a]}$

[a] G. Gómez Millán, DSc. K. Nieminen, DSc. S. Héllsten, Prof. H. Sixta

Department of Bioproducts and Biosystems

School of Chemical Engineering

Aalto University

Vuorimiehentie 1, 02150 Espoo (Finland)

*E-mail: gerardo.gomezmillan@aalto.fi

[b] J. P. Pokki

herbert.sixta@aalto.fi

Department of Chemical and Metallurgical Engineering

School of Chemical Engineering

Aalto University

PL 16100, 00076 Espoo (Finland)

Juha-pekka.pokki@aalto.fi

[c] G. Gómez Millán, Prof. J. Llorca

Department of Chemical Engineering, Institute of Energy Technologies and Barcelona Research Center in Multiscale Science and Engineering

Universitat Politècnica de Catalunya

Eduard Maristany 10-14, 08019 Barcelona (Spain)

[d] Alistair William Thomas King

Materials Chemistry Division, Chemistry Department

University of Helsinki

Al Virtasen Aukio 1, Helsinki (Finland)

\section{Abstract}

The production of furfural (FUR) from xylose was carried out using a biphasic batch reaction system. Isophorone, 2-methyltetrahydrofuran (2-MTHF) and cyclopentyl methyl ether (CPME) were used to extract FUR and enhance the overall furfural yield by limiting its degradation to humins. The effect of time, temperature, organic solvent and organicto-aqueous ratio on xylose conversion and FUR yield were investigated. Experiments conducted at three temperatures $\left(170,190\right.$ and $\left.210^{\circ} \mathrm{C}\right)$ were investigated in a stirred 
microwave-assisted batch reactor, which established the optimal conditions to obtain the highest FUR yield. The maximum FUR yields obtained from xylose were $78 \mathrm{~mol} \%$ when using CPME, 48 mol\% when using isophorone (due to its phase-behavior nature) and 71 mol\% when employing 2-MTHF with an aqueous to organic phase ratio of $1: 1$. Birch hydrolysate was also used to show the high furfural concentration that can be obtained in the bi-phasic system under optimized conditions. The present study suggests that CPME can be used as a green and efficient extraction solvent for the conversion of xylose into furfural without salt addition.

Keywords: xylose, furfural, prehydrolyzate liquor, 2-MTHF, CPME, isophorone

\section{Introduction}

Hemicellulose, one of the three major components in lignocellulosic biomass including cellulose and lignin, is a cross-linked fibrous amorphous polymer, consisting mostly of different pentoses $\left(\mathrm{C}_{5}\right)$ with some hexoses and uronic acids sugar monomers(Filiciotto et al., 2017). Hemicelluloses are the second most abundant natural polymer(Alexandra et al., 2006). The main $C_{5}$ sugars found in hemicellulose are xylose and arabinose. Although xylan (most abundant hemicellulosic polymer) and xylose have not yet been fully utilized in the paper industry, a significant amount of xylose, from the hydrolysis of woody biomass, is mixed with lignin-derived compounds and burned to provide process heat(Yang et al., 2015). Therefore, valorization of these compounds offers a new economic approach for new ideas and new markets.

According to the United States Department of Energy, furfural (furan-2-carbaldehyde, FUR) is one of the top 10 most rewarding bio-based platform molecules(Werpy and Petersen, 2004). FUR is industrially produced by the dehydration of xylose and other $\mathrm{C}_{5}$ - 
sugars usually found in hemicellulosic fractions of lignocellulosic biomass. FUR application range varies from the chemical industry (where is used as solvent and extracting agent), in the agrochemical sector FUR is employed as nematicide, fungicide and herbicide; it can also be involved in processes in the pharmaceutical and cosmetic industries(Peleteiro et al., 2016). Furthermore, FUR serves as a platform molecule to produce furfuryl alcohol (via hydrogenation)(Perez et al., 2017; Chen et al., 2016) with applications in the food industry as flavoring agent and in the biofuel sector. Other important molecules that can be potentially synthesized from FUR are: tetrahydrofurfuryl alcohol, furan, tetrahydrofuran, dihydropyran and furoic acid(Anonymous, 2000). Besides, FUR has been identified as a direct or indirect feedstock to more than 80 chemicals(Mariscal et al., 2016; Kamm, Gruber and Kamm, 2010). Consequently, FUR plays a major role as platform molecule in future bio-refineries developments(Filiciotto et al., 2017).

In the commercial process, FUR yield does not exceed $50 \mathrm{~mol} \%$ and involves several environmental issues, such as toxic effluents derived from mineral acids (sulfuric or hydrochloric acid) at temperatures of approximately $200^{\circ} \mathrm{C}$. Moreover, the consumption of high stripping-steam to FUR ratios raises significant energy consumption of the fuel employed to generate the steam. In order to overcome these challenges, new methodologies based on the use of easily-separable solid acid catalysts (e.g. zeolites(Kim et al., 2011; Xue et al., 2017; Bruce et al., 2016; Ennaert et al., 2016; Konwar et al., 2015; Metkar et al., 2015; Paniagua et al., 2015; Lessard et al., 2010; Ferreira et al., 2013; Lima et al., 2010; Lima, Pillinger and Valente, 2008; O'Neill et al., 2009), sulfonated graphenes(Garg, Bisht and Ling, 2014; Lam et al., 2012; Suganuma et al., 2011; Lam et 
al., 2011), sulfated zirconia(Perez et al., 2017; Dias et al., 2007; Yadav and Nair, 1999), alumina(You, Kim and Park, 2014), coated activated carbon(Sairanen et al., 2013; Konwar et al., 2015), among others)(Filiciotto et al., 2017) and ionic liquids(Peleteiro et al., 2016) suggest operational improvements involving green principals(Ahluwalia and Kidwai, 2004). Nevertheless, the unknown consequences of long-term use of ionic liquids, together with their elevated cost and yet inefficient recovery and recycling, set significant drawbacks to scale up their development.

Besides the limited FUR yields are partially due to the formation of insoluble polymers (humins). These humins are decomposition products of both xylose and FUR which react via resinification or condensation(Filiciotto et al., 2017; van Zandvoort et al., 2013; Rasmussen, Sørensen and Meyer, 2014). Several studies have suggested ways to inhibit the formation of humins and subsequently increase the FUR yield. One approach is to selectively extract the FUR from the aqueous solution into an organic phase(Weingarten et al., 2010). Trimble and Dunlop(Trimble and Dunlop, 1940) were the pioneers to implement this idea using ethyl acetate as the extracting media. Subsequent research included studies on various organic solvents such as 1-butanol(Zhang et al., 2012), Yvalerolactone(Dhepe and Sahu, 2010; Bruce et al., 2016), cyclohexanol(Mittal et al., 2017), methyl isobutyl ketone (MIBK)(Weingarten et al., 2010; Mittal et al., 2017), dimethyl sulfoxide (DMSO)(Dias et al., 2006; Dias, Pillinger and Valente, 2005b; Dias, Pillinger and Valente, 2005a) and widely-used toluene(Mittal et al., 2017). However, most of these studies involve the addition of salts due to the high solubility of organic solvents in water, in order to increase the partition coefficient. Hence producing high salt waste after work-up and possible deactivation of acid sites on solid acid catalysts(Argyle and 
Bartholomew, 2015). Besides, green solvents from renewable sources such as 2-MTHF and CPME(Watanabe, 2013; Tenne et al., 2013; Campos Molina et al., 2012) are commercially available offering sustainable alternatives in order to extract FUR without the addition of salts due to its aqueous-immiscibility nature and provide a superior phase separation at the organic-water interface without forming emulsions(Tenne and Schwaneberg, 2012).

The aim of this work is to evaluate the production of FUR from xylose using a biphasic system in which FUR is extracted into a water-immiscible solvent increasing the yield of the process. Besides, the prevention of salt addition offers a greener perspective in the FUR production. Furthermore, the system would reduce FUR decomposition reactions via condensation and resinification. At normal conditions, 2-MTHF has a solubility in water of $14 \mathrm{~g} / 100 \mathrm{~g}$ at $20^{\circ} \mathrm{C}$ (Pace et al., 2001), Isophorone has a solubility of $1.2 \mathrm{~g} / 100 \mathrm{~g}$ at $20^{\circ} \mathrm{C}$ (Ershova et al., 2018) and CPME of $1.1 \mathrm{~g} / 100 \mathrm{~g}$ at $23^{\circ} \mathrm{C}$ (Campos Molina et al., 2012).

\section{Experimental Section}

\section{Analysis}

\section{Materials}

D-Xylose powder (99\%), isophorone, 2-MTHF and CPME were purchased from Sigma Aldrich.

D-Xylose powder was used in the experiments without further purification. Formic acid (98\%, Sigma Aldrich), levulinic acid (99\%, Sigma Aldrich) and acetic acid (99\%, HPLC 
grade, Sigma Aldrich) were used for the preparation of calibration standards for HPLC analysis. Millipore grade water was used for preparing the solutions.

The birch hydrolysate was supplied by Stora Enso (Stora Enso, Imatra, Finland), which was used for the dehydration reaction experiments.

\section{Methods}

\section{Xylose Dehydration Reaction Experiments in Biphasic System}

Single containing D-xylose solution in a concentration typical for biomass hydrolysate $\left(186 \mathrm{mmol} \mathrm{I}^{-1}\right)$ was freshly prepared before the experiments. These experiments can be considered as an auto-catalyzed reaction system where some side products (namely carboxylic acids) or intermediates, formed during the reaction, may have a catalytic effect(Lamminpää, Ahola and Tanskanen, 2012; Dussan et al., 2016). In a typical experiment, the samples were prepared by heating $3 \mathrm{ml}$ of an aqueous solution of 186 mmol $\mathrm{I}^{-1}$ xylose using a borosilicate glass reactor $\left(\mathrm{V}=10 \mathrm{~cm}^{3}\right)$ with magnetic stirring $(600$ $\min ^{-1}$ ), an irradiation power of $\leq 850 \mathrm{~W}$ for maximum $2 \mathrm{~min}$ and microwave-assisted heating (Monowave 300, Anton Paar GmbH, Graz, Austria). The prepared solutions were tested for FUR yield, selectivity and xylose conversion at the reaction temperatures of 170,190 and $210^{\circ} \mathrm{C}$ with different reaction times in the range of $30-240 \mathrm{~min}$. The reaction vial was rapidly cooled after the reaction by compressed air inside the reactor until it reached $60{ }^{\circ} \mathrm{C}$. The highest temperature and the longest reaction time studied at the present work were $210^{\circ} \mathrm{C}$ and 240 min, respectively.

\section{Birch Hydrolysate Dehydration Reaction Experiments in Biphasic System}

The birch hydrolysate was filtered by using a glass filter with porosity 4 (Duran). The composition of the liquor was determined according to the analytical method NREL/TP- 
510-42623(Sluiter et al., 2008). The concentration of monomeric sugars was measured by high-performance anion exchange chromatography with pulse amperometric detection (HPAEC-PAD) by using a Dionex ICS-3000 column.

\section{Determination of FUR and by-products}

Samples for analysis were drawn from both the organic phase (top) and aqueous phase (bottom) after microwave heating. Xylose, carboxylic acids (formic, acetic and levulinic acids) and FUR from aqueous phase were analyzed separately by High Performance Liquid Chromatography (HPLC) operating a Dionex UltiMate 3000 HPLC (Dionex, Sunnyvale, CA, USA) device equipped with refractive index (RI) and ultraviolet (UV) diode array detectors. Product separation was achieved on a HyperRez XP Carbohydrate $\mathrm{Ca}^{+}$ column (Thermo Scientific, Waltham, MA, USA). Aqueous sulfuric acid $\left(0.005 \mathrm{~mol}^{-1}\right)$ was used as eluent with a flow rate of $0.8 \mathrm{ml} \mathrm{min}^{-1}$. The column temperature and the RIdetector temperature were set to $70{ }^{\circ} \mathrm{C}$ and $55^{\circ} \mathrm{C}$, respectively. The FUR and hydroxymethylfurfural (HMF) concentration was determined by the UV-detector at a wavelength of $280 \mathrm{~nm}$. The xylose concentration was analyzed simultaneously by the RIdetector and the UV-detector at $210 \mathrm{~nm}$ for a crosscheck(Givry, Bliard and Duchiron, 2007).

FUR from the organic phase was analyzed by gas chromatography with a flame ionization detector (GC-FID) relative to iso-butanol as internal standard (IS). The column used was a DB-WAXetr (30 m, $0.32 \mathrm{~mm}$ i.d., $1 \mu \mathrm{m}$ film thickness) from Agilent Technologies Inc. The injected samples $(0.5 \mu \mathrm{L})$ were subjected to a splitless ratio in the inlet maintained at $300^{\circ} \mathrm{C}$. Helium was used as the carrier gas. The oven was initially maintained at $40^{\circ} \mathrm{C}$ for $4 \mathrm{~min}$, after which the temperature was increased to $200{ }^{\circ} \mathrm{C}$ at $30^{\circ} \mathrm{C} \mathrm{min}-1$. The FID 
was operated at $300{ }^{\circ} \mathrm{C}$ with hydrogen, air, and helium delivered at $30 \mathrm{~mL} \mathrm{~min}{ }^{-1}, 400 \mathrm{ml}$ $\min ^{-1}$, and $25 \mathrm{ml} \mathrm{min}^{-1}$, respectively.

In this study conversion is defined in terms of moles of reactant converted per unit volume of reactor. Selectivity, at an instant, is the generated amount of a desired product relative to the generation of some undesired product on a molar basis. Yield is the amount in moles of desired product (FUR) produced relative to the amount of the key reactant (xylose)(Pirola, Rossetti and Ragaini, 2013). The following equations have been used for the mathematical evaluation of the obtained results:

$$
\begin{aligned}
& X_{x y l}=\frac{c_{x y l}^{i n}-c_{x y l}^{f}}{c_{x y l}^{i n}} \times 100[\%] \\
& S_{x y l}^{f u r}=\frac{c_{f u r}}{c_{x y l}^{i n}-c_{x y l}^{f}} \times 100[\%] \\
& Y_{f u r}=\frac{c_{f u r}}{c_{x y l}} \times 100[\%]
\end{aligned}
$$

where $\mathrm{X}, \mathrm{S}, \mathrm{Y}$ are the- conversion of xylose, selectivity to FUR and FUR yield, respectively; $c$ is the- concentration in $\mathrm{mmol} \mathrm{I}^{-1}$ (the subscripts to be read as follows: $x y l$, fur, in, $f$ are the- xylose, FUR, initial, final).

\section{Furfural Decomposition Reaction Experiments in Biphasic System.}

FUR decomposition reactions were conducted using a $10 \mathrm{ml}$ borosilicate glass reactor with magnetic stirring $\left(600 \mathrm{~min}^{-1}\right)$ and microwave-assisted heating (Monowave 300, Anton Paar GmbH, Graz, Austria). The vials were filled with $1.5 \mathrm{ml}$ of $5 \mathrm{wt} \%$ FUR solution and $1.5 \mathrm{ml}$ of the organic solvent. The prepared solutions in the biphasic system were tested for FUR concentration at the reaction temperatures of 170,190 and $210^{\circ} \mathrm{C}$ with different reaction times in the range of $30-180 \mathrm{~min}$. The reaction vial was rapidly cooled to $60^{\circ} \mathrm{C}$ 
after the reaction via a stream of compressed air that was blown onto the reactor. Samples were stored at $0{ }^{\circ} \mathrm{C}$ until analyzed.

\section{Results and Discussion}

\section{Furfural partitioning in a Biphasic Reactor System.}

The partitioning of FUR in different organic solvents was investigated by conducting hydrothermal reactions wherein a solution of $5 \mathrm{wt} \%$ FUR in water was heated with isophorone, 2-MTHF, and CPME for $30 \mathrm{~min}$ at $190^{\circ} \mathrm{C}$ at five different ratios of aqueous to organic solvent: $1: 5,1: 2,1: 1,2: 1$ and $5: 1(\mathrm{v} / \mathrm{v})$. Figure 1 shows the FUR partition coefficients $(\mathrm{P})$ obtained with the three organic solvents, where $P$ was calculated using eq. 6(Mittal et al., 2017).

$P=\frac{[F U R]_{\text {org }}}{[F U R]_{a q}}$

A FUR partition coefficient of 9.1 was obtained with an aqueous to isophorone fraction ratio of $1: 5$. This value decreased to $7.5,8.4,6.9$ and 6.6 as the aqueous to isophorone fraction ratio increased to 1:2, 1:1, 2:1 and 5:1, respectively. For 2-MTHF (4.6) and CPME (3.8) lower partition coefficients were obtained compared to isophorone.

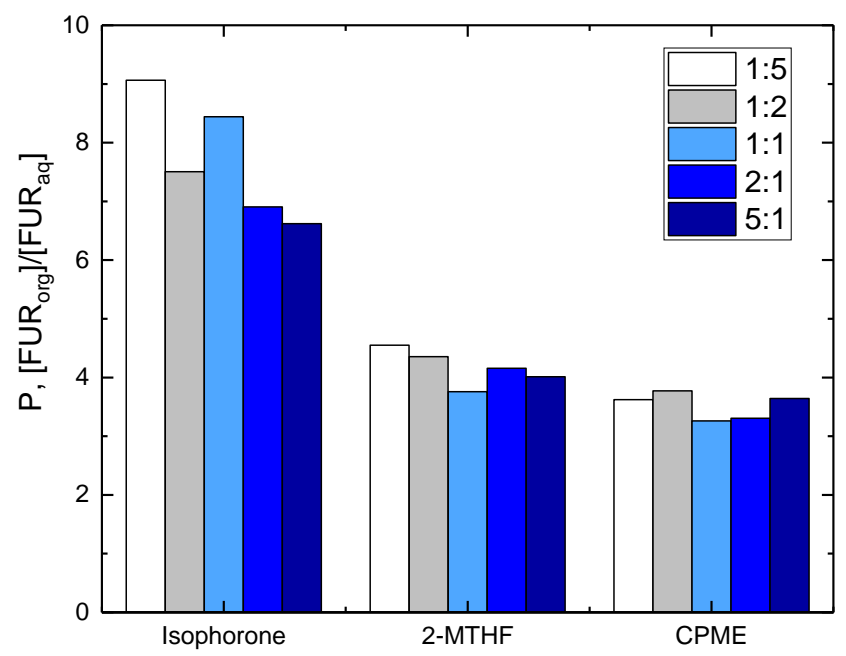


Figure 1. Partition coefficients for furfural among isophorone, 2-MTHF and CPME. Partition coefficients were determined for a solution of $5 \mathrm{wt} \%$ furfural in water heated for $30 \mathrm{~min}$ at $190^{\circ} \mathrm{C}$ (and then cooled down to $60^{\circ} \mathrm{C}$ ) at five different ratios of aqueous to organic solvent: 1:5, 1:2, 1:1, 2:1 and 5:1 (v/v).

\section{Furfural Production from Xylose}

The effect of xylose dehydration on FUR production was studied in biphasic systems made with isophorone, 2-MTHF or CPME serving as the organic phase and an aqueous xylose solution.

\section{Effect of organic phase and aqueous to organic phase ratio}

The effect of different organic solvents and an aqueous solution of $186 \mathrm{mmol} \mathrm{I}^{-1}$ was studied in biphasic systems at $190^{\circ} \mathrm{C}$ in $30 \mathrm{~min}$. For this, three water-immiscible solvents were studied: isophorone, 2-methyltetrahydrofuran (2-MTHF) and cyclopentyl methyl ether (CPME). Simultaneously, the effect of aqueous to organic phase ratio on xylose conversion and FUR production was investigated. For this, five ratios of aqueous to organic phase $(1: 5,1: 2,1: 1,2: 1,5: 1 ; v / v)$ were planned. The FUR yields are shown in Figure 2 and are calculated using equation 3.

It can be seen in Figure 2 that the FUR yield increases as the aqueous to organic ratio increases from 1:5 up to 1:1 independently of the organic solvent. It can be assumed that the FUR yield depends on the available xylose for aqueous to organic ratios of 1:5 and $1: 2$. For the aqueous to organic ratios of $2: 1$ and $5: 1$, we suggest that decomposition products are formed in the aqueous phase that hindered a higher FUR yield. The highest FUR yield (14\%, Figure 2a) is reached (at $190{ }^{\circ} \mathrm{C}$ in $30 \mathrm{~min}$ ) when employing isophorone in an aqueous to organic phase ratio of 1:1. When 2-MTHF is employed (Figure 2b), the highest FUR yield (13\%) is also reached in an aqueous to organic phase ratio of 1:1. When CPME is used (Figure 2c), a FUR yield of $26 \%$ is reached at $190^{\circ} \mathrm{C}$ in $30 \mathrm{~min}$. 

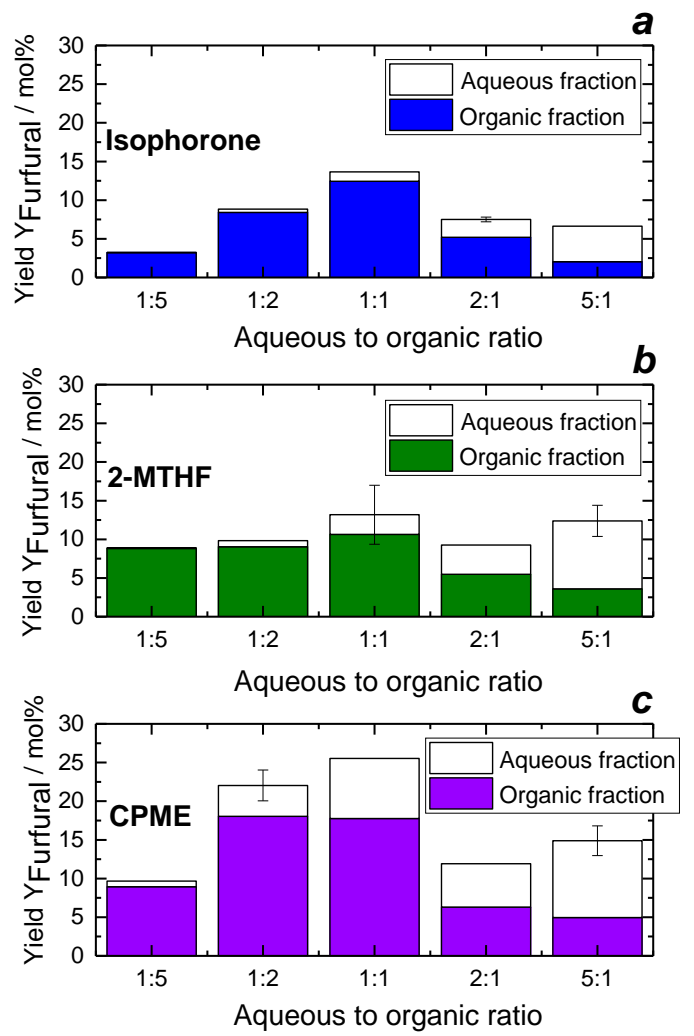

Figure 2. Effect of aqueous to organic ratio on FUR yield when using isophorone (a), 2-MTHF (b) and CPME (c) as organic phase. The effect was determined for a solution of xylose $\left(186 \mathrm{mmol}^{-1}\right)$ heated at $190{ }^{\circ} \mathrm{C}$ in $30 \mathrm{~min}$ at five different ratios of aqueous to organic solvent: 1:5, 1:2, 1:1, 2:1, 5:1 (v/v). The error bars shown are one standard deviation from duplicate analyses.

\section{Effect of reaction temperature}

The effect of reaction temperature on the dehydration of xylose and the production of FUR was studied by conducting reactions between 100 and $200{ }^{\circ} \mathrm{C}$ for $30 \mathrm{~min}$ employing a $186 \mathrm{mmol} \mathrm{I}^{-1}$ xylose solution in a bi-phasic mixture (water-organic solvent, $5: 1 \mathrm{v} / \mathrm{v}$ ) under microwave irradiation (Figure A1 in the Supporting Information). D-xylose is not soluble in the organic phase(Guenic et al., 2015). The FUR yield varied between 0 and $23 \mathrm{~mol} \%$ (Fig. A1a). The effect of reaction temperature on FUR yield, xylose conversion and selectivity to FUR when working with an aqueous to organic ratio of $5: 1$ 
was further investigated. A low FUR yield was obtained from 100 to $150^{\circ} \mathrm{C}$ (approximately $0 \%$ ). The reason for lower FUR yield at the low reaction temperature was due to incomplete xylose conversion (below 15\%, Fig. A1b). The highest FUR yield when employing CPME and 2-MTHF is $23 \%$ (at a xylose conversion of $57 \%$ and $49 \%$, respectively) in $30 \mathrm{~min}$ at $200{ }^{\circ} \mathrm{C}$, and when using isophorone is $18 \%$ (at a xylose conversion of $50 \%$ ) at $200{ }^{\circ} \mathrm{C}$ (in $30 \mathrm{~min}$ ).

\section{Effect of reaction time}

The effect of reaction time on the production of FUR was studied by conducting reactions between 30 to $180 \mathrm{~min}$ at 170,190 and $210^{\circ} \mathrm{C}$ with isophorone, 2-MTHF and CPME with a xylose solution of $186 \mathrm{mmol} \mathrm{I}^{-1}$. Due to the low vapor pressure of 2-MTHF, reactions using this organic solvent at reaction temperatures of $210^{\circ} \mathrm{C}$ were not possible to perform. Figure 3 shows the effect of reaction time when using CPME on FUR yield, xylose conversion and selectivity to FUR. In agreement with previous studies(Danon et al., 2014), FUR yield and xylose conversion were observed to be strongly influenced by the reaction temperature.

Figure 3 displays the effect of reaction time on FUR yield, xylose conversion and selectivity to FUR at 170,190 and $210^{\circ} \mathrm{C}$ when using CPME as organic solvent in an aqueous to organic phase ratio of 1:1. As seen in Figure 3a, after the first 60 min of the hydrothermal reaction the FUR yield was increased up to four times by increasing the temperature from 170 to $190^{\circ} \mathrm{C}$. The highest FUR yield (78\%) was reached at $190{ }^{\circ} \mathrm{C}$ in $3 \mathrm{~h}$. The maximum selectivity (Figure 3c) to FUR formation was $93 \%, 81 \%$ and $71 \%$ at temperatures of 170,190 and $210^{\circ} \mathrm{C}$, respectively. 
It can be seen, that at times longer than $120 \mathrm{~min}$, the FUR yield obtained at $190^{\circ} \mathrm{C}$ surpasses the FUR yield obtained at $210^{\circ} \mathrm{C}$. Under high reaction temperatures $\left(210^{\circ} \mathrm{C}\right)$ we assume that CPME does not extract FUR as efficiently. Therefore FUR tends to stay in the aqueous phase rather than in the organic phase, hence decomposition reactions of FUR occur faster.

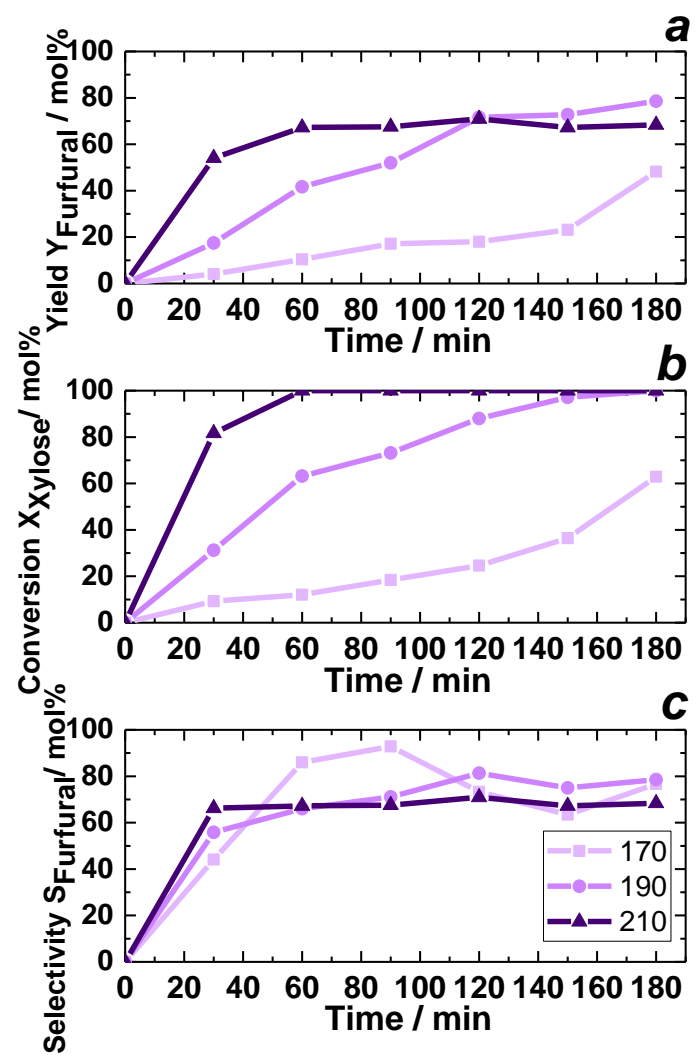

Figure 3. Effect of temperature and reaction time on (a) FUR yield, (b) xylose conversion, (c) selectivity to FUR in the dehydration of $28 \mathrm{~g} \mathrm{t}^{-1}$ xylose when using CPME as organic solvent with an aqueous to organic phase ratio of 1:1. Lines are to guide the eye.

When using isophorone as water-immiscible solvent, the results can be seen in Figure 4. Figure 4a shows that for the first $60 \mathrm{~min}$ of the treatment the FUR yield was increased up to four times by increasing the temperature from 170 to $190{ }^{\circ} \mathrm{C}$ when employing isophorone to aqueous fraction ratio of 1:1. The highest FUR yield (49\%) was 
reached at $190{ }^{\circ} \mathrm{C}$ in $3 \mathrm{~h}$. The maximum selectivity (Figure 4c) to FUR formation was $48 \%, 54 \%$ and $43 \%$ at temperatures of 170,190 and $210{ }^{\circ} \mathrm{C}$, respectively. A similar phenomenon occurred when employing isophorone as observed with CPME. Under high reaction temperatures $\left(210^{\circ} \mathrm{C}\right)$, FUR tends to stay in the aqueous phase rather than in isophorone, hence decomposition of FUR occurs faster. In comparison to the performance of isophorone to 2-MTHF and CPME, it might be that FUR enters the organic phase but undergoes degradation in the presence of the solubilized water within isophorone, afterwards FUR precipitates out once a certain molecular weight is reached.

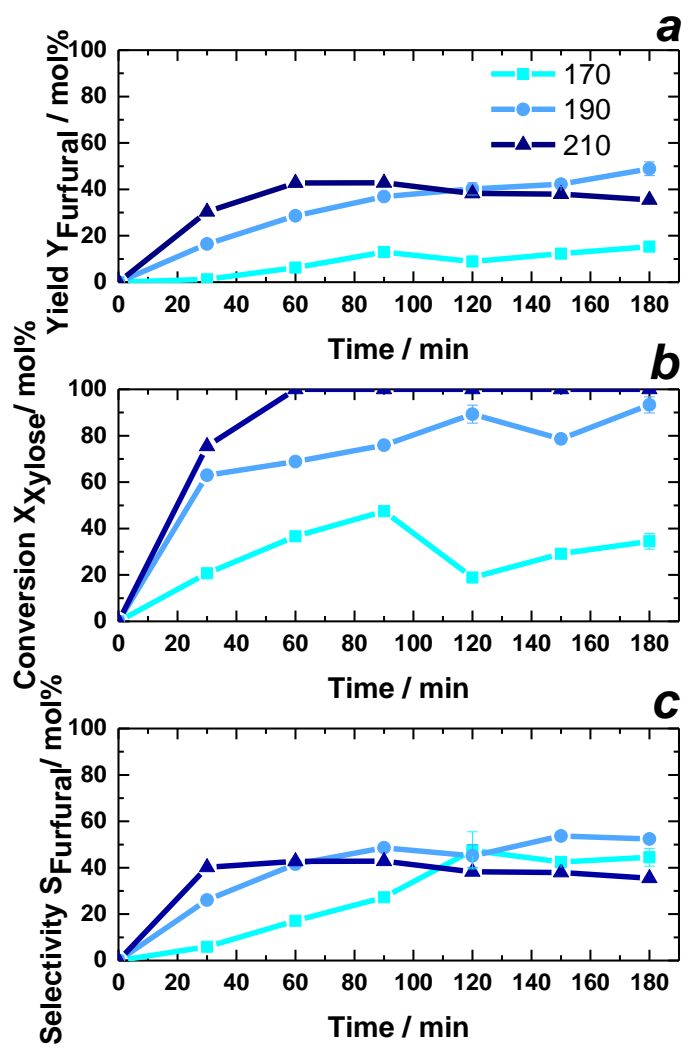

Figure 4. Effect of temperature and reaction time on (a) FUR yield, (b) xylose conversion, (c) selectivity to FUR in the dehydration of $186 \mathrm{mmol} \mathrm{l}^{-1}$ xylose when using isophorone as organic solvent with an aqueous to organic phase ratio of 1:1. Lines are to guide the eye. 
Figure 5 shows FUR yield, xylose conversion and selectivity to FUR when employing 2-MTHF. Figure $5 \mathrm{a}$ shows that the first $60 \mathrm{~min}$ of the treatment the FUR yield was increased up to two times by increasing the temperature from 170 to $190{ }^{\circ} \mathrm{C}$ when employing 2-MTHF to aqueous fraction ratio of $1: 1$. The highest FUR yield $(71 \%)$ was reached at $190{ }^{\circ} \mathrm{C}$ in $3 \mathrm{~h}$. The maximum selectivity (Figure $5 \mathrm{c}$ ) to FUR formation was $58 \%$ and $80 \%$ at temperatures of 170 and $190^{\circ} \mathrm{C}$, respectively. Due to the low vapor pressure of 2-MTHF, reactions using this organic solvent at reaction temperatures of $210{ }^{\circ} \mathrm{C}$ were not possible to perform.

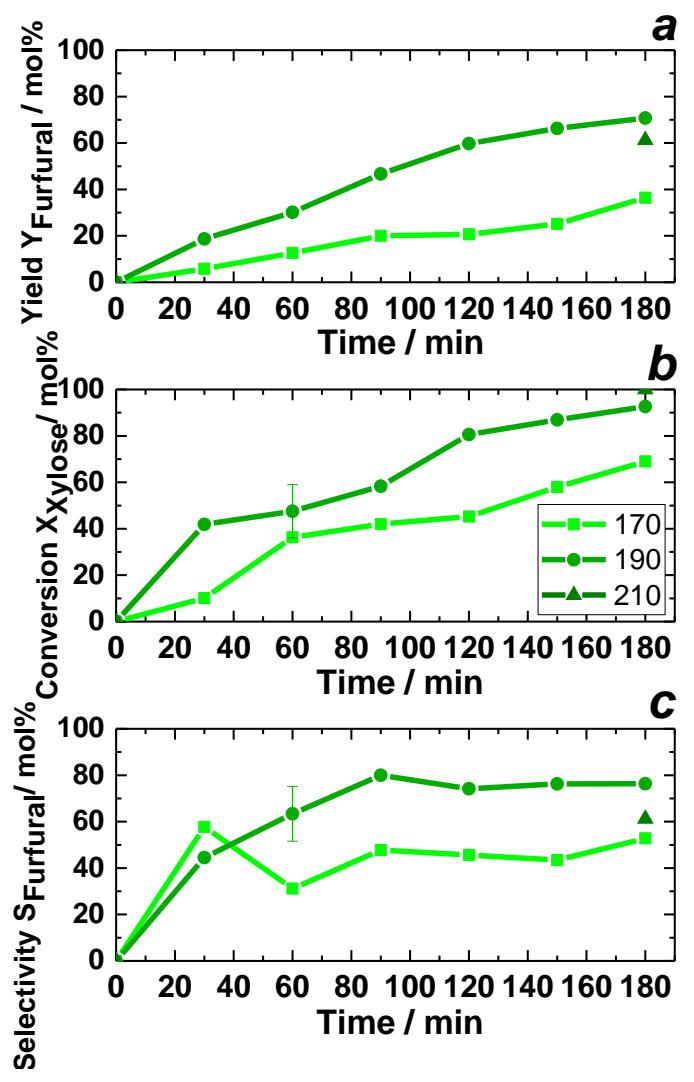

Figure 5. Effect of temperature and reaction time on (a) FUR yield, (b) xylose conversion, (c) selectivity to FUR in the dehydration of $186 \mathrm{mmol} \mathrm{I}^{-1}$ xylose when using 2-MTHF as organic solvent with an aqueous to organic phase ratio of 1:1. Lines are to guide the eye. 


\section{Furfural decomposition in the bi-phasic system}

In order to extend the understanding about the behavior of FUR under the conditions employed in the microwave-assisted reaction when an organic solvent is present, knowledge on its degradation rate is desired. The FUR degradation experiments were performed for the auto-catalyzed reactions using CPME and isophorone at the temperatures of 170,190 and $210{ }^{\circ} \mathrm{C}$. The experimental data showing the remaining fractions of FUR found in the aqueous and organic phases at various reaction times are presented in Fig. $6 \mathrm{a}$ and 6b, when adding isophrone and CPME, respectively. The figures illustrate the effect of the treatment temperature and the usage of $1: 1$ aqueous to organic phase fraction ratio on the degradation rate of FUR. The results show a clear dependency of FUR degradation on the temperature, similarly to the data presented in earlier reports in monophasic systems(Jing and Lü, 2007; Williams and Dunlop, 1948; Marcotullio et al., 2009; Danon, van der Aa and de Jong, 2013; Lamminpää, Ahola and Tanskanen, 2014). It can be seen that the implementation of a higher temperature increases the FUR degradation for both auto-catalyzed with isophorone and CPME. In addition, the results show that FUR is decomposed more rapidly in the presence of isophorone. The highest degree of degradation, $38 \%$, was observed at $210{ }^{\circ} \mathrm{C}$ after $180 \mathrm{~min}$. When CPME was employed as organic solvent, the highest degree of degradation was below $12 \%$. 

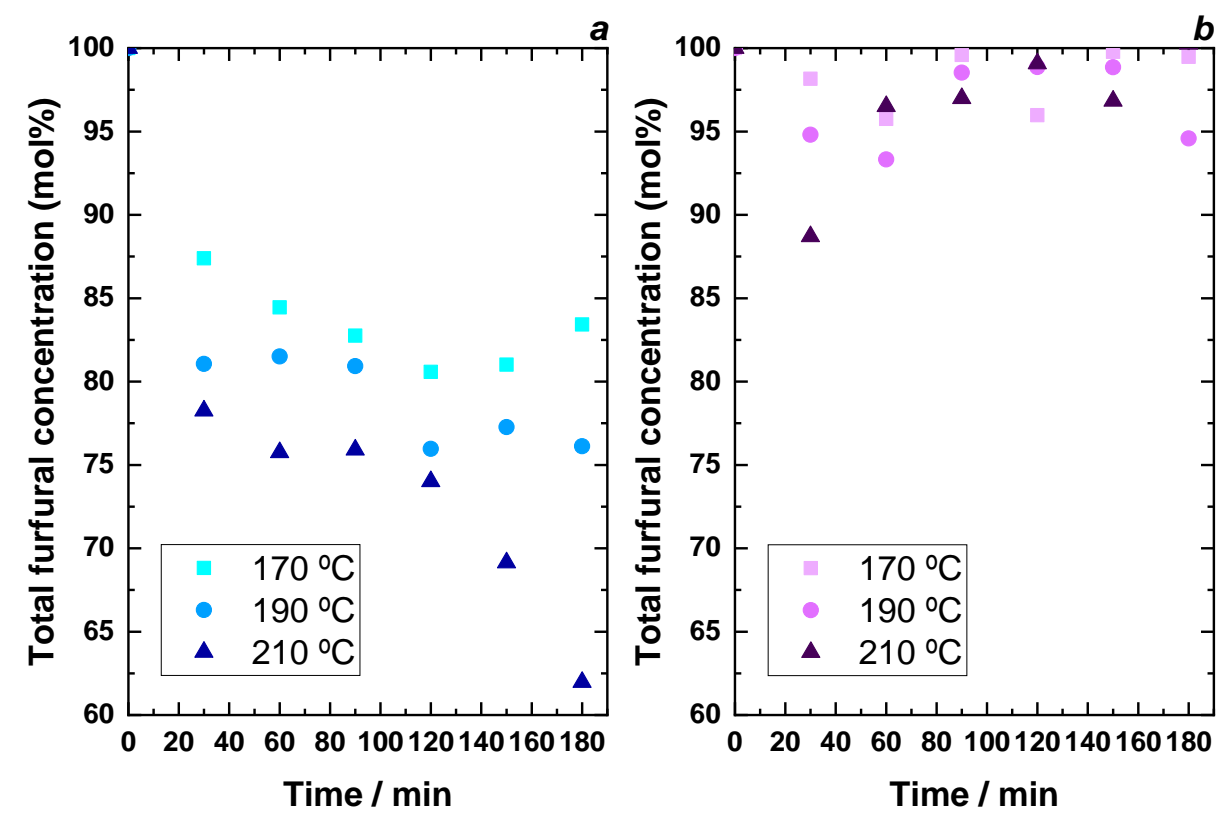

Figure 6. The remaining furfural concentration at various reaction times during auto-catalyzed degradation when employing isophorone (a) and CPME (b) to aqueous phase of $1: 1(\mathrm{v} / \mathrm{v})$. The decomposition of furfural was determined for a solution of $5 \mathrm{wt} \%$ furfural (squares $-170{ }^{\circ} \mathrm{C}$, circles -190 ${ }^{\circ} \mathrm{C}$, triangle $\left.-210^{\circ} \mathrm{C}\right)$.

In order to confirm FUR decomposition in the presence of isophorone, a temperature level study was performed from $110{ }^{\circ} \mathrm{C}$ to $210^{\circ} \mathrm{C}$ in 60 min when employing an aqueous to organic phase ratio of 1:1 (v/v). Fig. A2 (in the Supporting Information) shows that FUR decomposes linearly under the experimental conditions reaching the highest degree of degradation (24\%) at $210^{\circ} \mathrm{C}$ in $60 \mathrm{~min}$.

\section{Liquid-liquid equilibrium study}

To get FUR from aqueous phase to organic phase the distribution should favor high solute distribution coefficients of FUR when defined as in Eq. (7)

$K_{i}=\frac{w_{i, \text { organic }}}{w_{i, \text { aqueous }}}$ 
where i refers to any component in the mixture. Isophorone-FUR-water data at 30,50 and $70{ }^{\circ} \mathrm{C}$ was recently published by Ershova et al(Ershova et al., 2018) demonstrating that at the equilibrium state the aqueous phase contains around $1 \mathrm{wt} \%$ isophorone and around 0.8-3.8 wt\% FUR, whereas the organic phase contains 4.5-6.4 wt\% water. In contrast, CPME-FUR-water and 2-MTHF-FUR-water at 20, 50 and $70{ }^{\circ} \mathrm{C}$ have been recently reported(Männistö et al., 2017) . At the equilibrium state of 2-MTHF-FUR-water the aqueous phase contains from 1-11 wt\% 2-MTHF and approximate 1-9.9 wt\% FUR, whereas the organic phase contains $4.8-8.8 \mathrm{wt} \%$. In the case of CPME-FUR-water the aqueous phase contains less than $1 \mathrm{wt} \%$ CPME and around $1.7-11 \mathrm{wt} \%$ FUR, whereas the organic phase contains $0.8-6$ wt $\%$ water. Figures 7,8 and 9 summarize the measured (dots) and predicted (lines) LLE phase equilibrium.
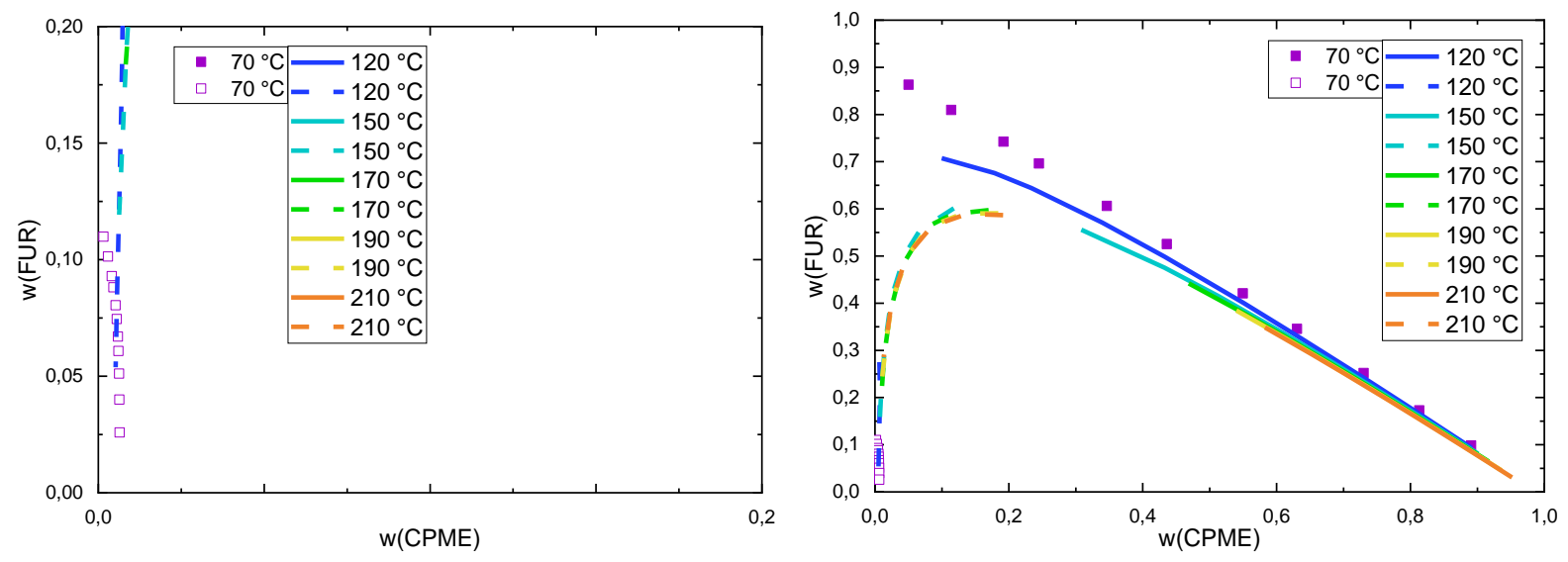

Figure 7. CPME and FUR binary LLE in mass fractions at atmospheric pressure. $70{ }^{\circ} \mathrm{C}$ Männisto et al.(Männistö, Pokki and Alopaeus, 2018), $120-210^{\circ} \mathrm{C}$ lines are extrapolated based on UNIQUAC model, filled symbol and solid line - organic (upper) phase, open symbol and dashed line - aqueous (lower) phase. Left figure shows the aqueous phase enlarged. 

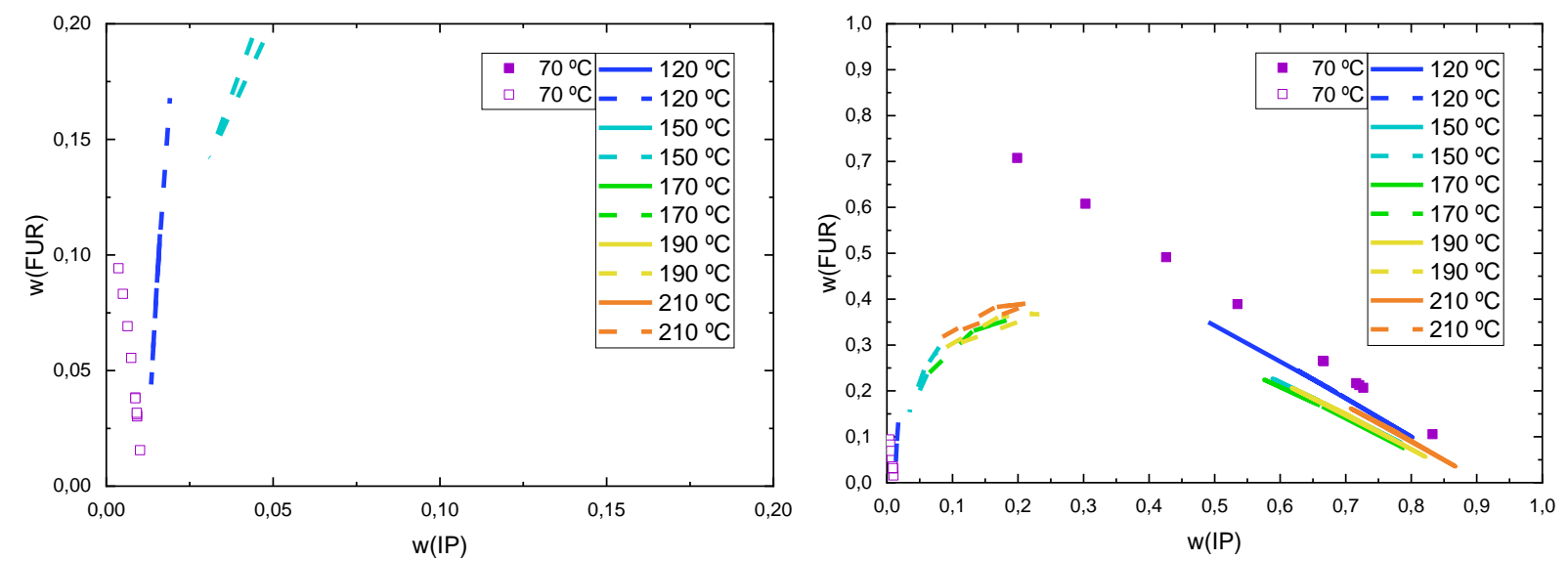

Figure 8. Isophorone (IP) and FUR binary LLE in mass fractions at atmospheric pressure. $70^{\circ} \mathrm{C}$ symbols from Ershova et al.(Ershova et al., 2018), $120-210^{\circ} \mathrm{C}$ lines are extrapolated based on UNIQUAC model, filled symbol and solid line - organic (upper) phase, open symbol and dashed line - aqueous (lower) phase. Left figure shows the aqueous phase enlarged.
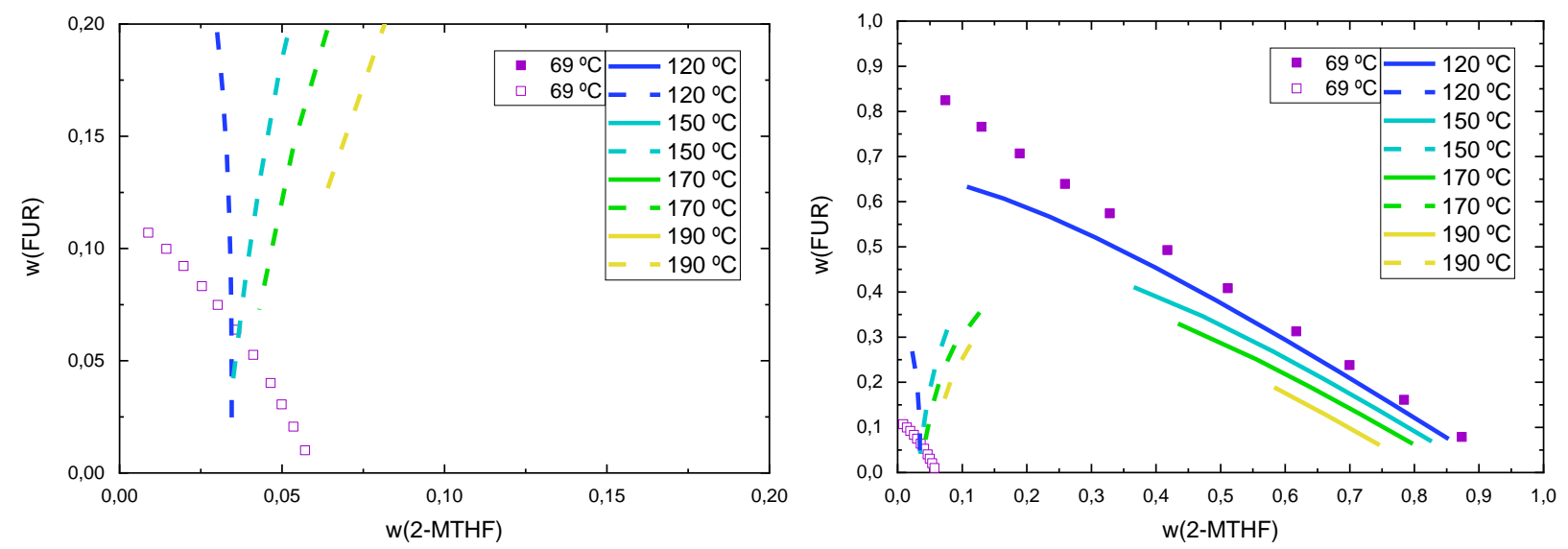

Figure 9. 2-MTHF and FUR binary LLE in mass fractions at atmospheric pressure. $70^{\circ} \mathrm{C}$ symbols from Männisto et al.(Männistö, Pokki and Alopaeus, 2018), 120-210 ${ }^{\circ} \mathrm{C}$ lines are extrapolated based on UNIQUAC model, filled symbol and solid line - organic (upper) phase, open symbol and dashed line aqueous (lower) phase. Left figure shows the aqueous phase enlarged.

From the Figures 7-9 it can be seen that the slope of tie-line changes from positive to negative as temperature increases. It means that the distribution coefficient of FUR is higher than one close to room temperature but at the reaction temperature of this work it is less than one. The calculated distribution coefficients are presented in Fig. 10. 

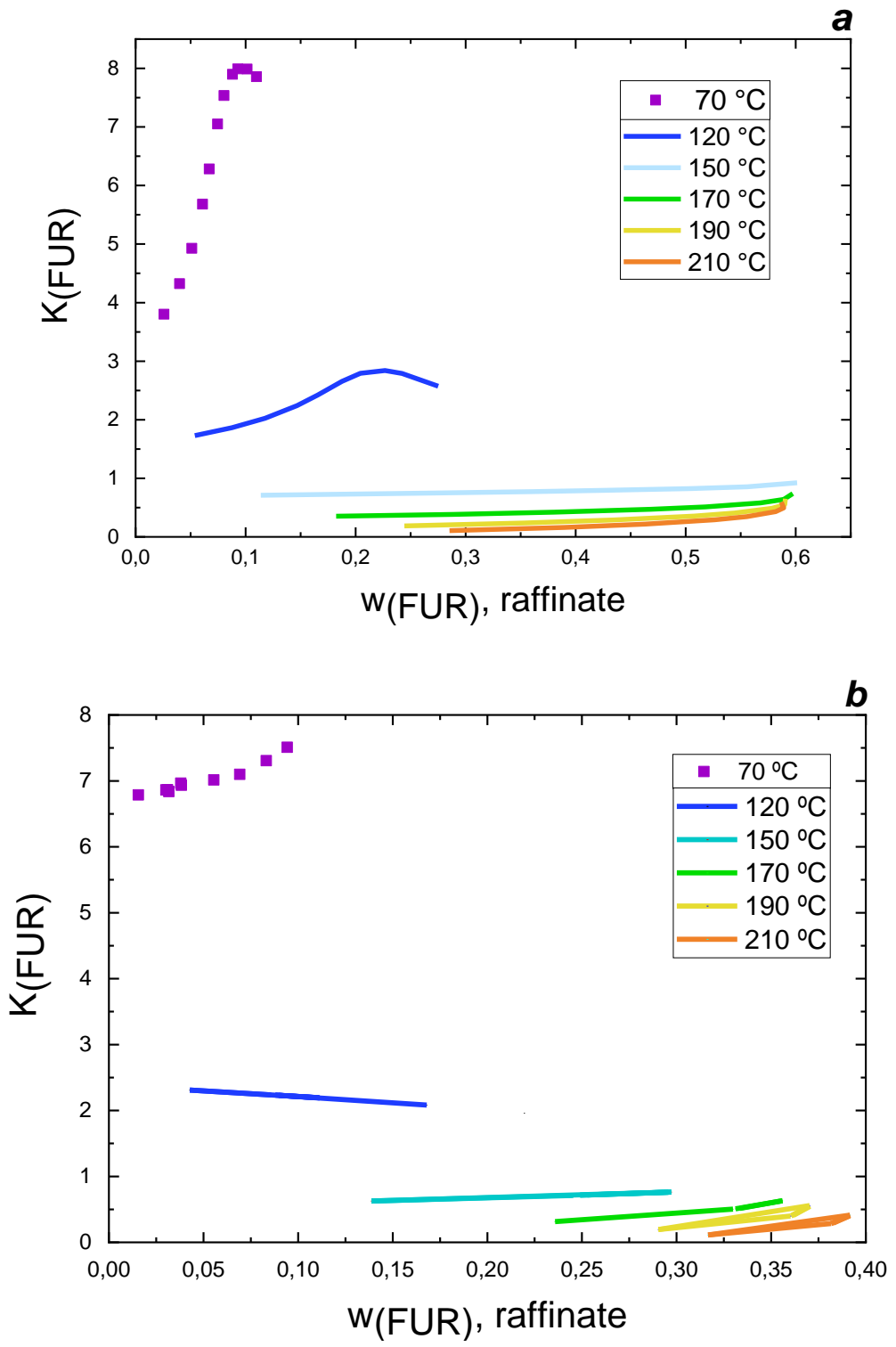


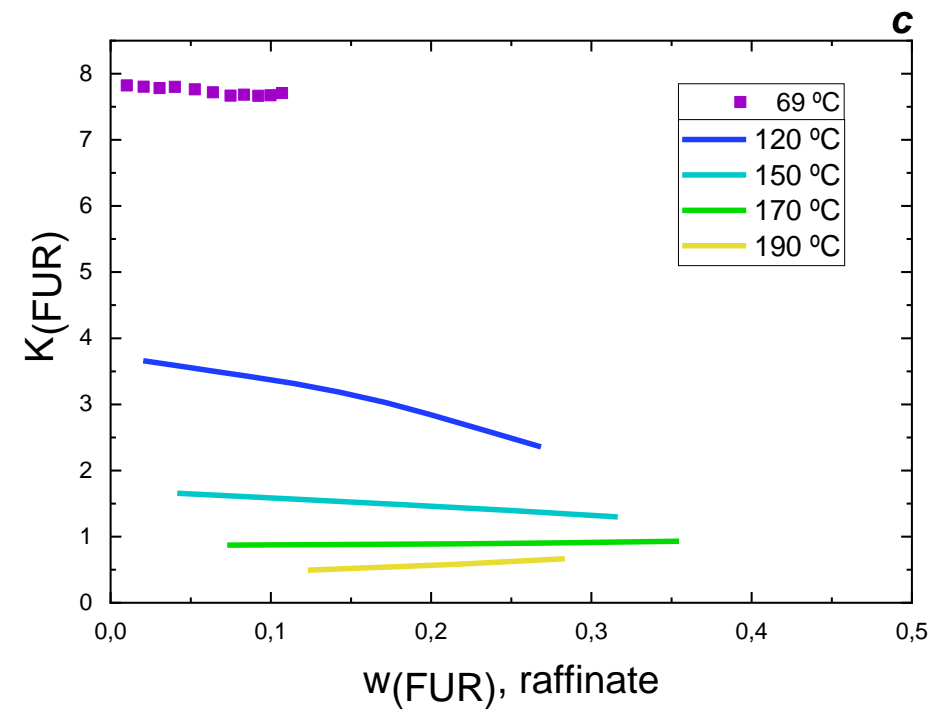

Figure 10. Distribution coefficient $K$ for FUR in raffinate in the system when: a- CPME, b-isophorone and c- 2-MTHF are added to the system.

Based only on liquid-liquid equilibria (LLE) 2-MTHF gives $\mathrm{K}$ values of FUR higher than one at $150^{\circ} \mathrm{C}$ but $\mathrm{CPME}$ and isophorone less that one. At $170^{\circ} \mathrm{C}$ and higher temperature all solvents give the K-value of FUR less than one. In industrial practice, this could mean that lower temperatures are preferred for the FUR to be extracted adequately by the organic phase.

In the present work from the three water-immiscible organic solvents studied, isophorone shows a higher distribution coefficient of FUR, however CPME demonstrates a higher selectivity towards FUR without decomposition. This suggests that FUR undergoes decomposition reactions, potentially including isophorone as a co-reactant. Alternatively, the rate of degradation of FUR may be increased by an increasing content of water at temperatures approaching $200{ }^{\circ} \mathrm{C}$. The first option was investigated by NMR analysis of the degradation of FUR: isophorone molar ratios of $1: 1$ and $1: 10$ at $190{ }^{\circ} \mathrm{C}$ over 30 min and 120 min (Supporting Information Figs. A4-A6). A potential mechanism for this 
degradation might be via Diels-Alder cycloaddition, a mechanism that is implicated in degradation of FUR itself. However, isophorone is a somewhat hindered dienophile, having a methyl group in the 3-position. High reactivity under ambient conditions is not expected. Despite colourisation of the solutions after heating, ${ }^{1} \mathrm{H}$ NHMR analysis (in DMSO-d 6 at $27^{\circ} \mathrm{C}$ ) showed that no new decomposition products were formed (Supporting Information Figs. A5 \& A6) and no precipitate was visible that might indicate significant condensation of FUR. Instad, a small proportion of the FUR is likely decomposing to give compounds with high molar extinction coefficients in the visible region. Presence of water in the organic phase is another potential reason for losses of FUR. However, there is no literature LLE data available for water and isophorone at the higher temperatures studied. The maximum temperatures quoted in the literature are only up to $343 \mathrm{~K}$ (Ershova et al., 2018). The changing miscibility of water and isophorone up to $190{ }^{\circ} \mathrm{C}$ was crudely assessed by heating a mixture of isophorone $(1 \mathrm{ml})$ and water $(1 \mathrm{ml})$ in sealed narrow bore sample vials (Supporting Information Fig. A7) from $110{ }^{\circ} \mathrm{C}$ to $190{ }^{\circ} \mathrm{C}$, with $5 \mathrm{~min}$ equilibration time every $10^{\circ} \mathrm{C}$. At room temperature and even up to $110^{\circ} \mathrm{C}$ the mixtures clearly form separate phases. however, as the temperature moves from $150-190^{\circ} \mathrm{C}$ the organic phase becomes cloudy, indicating dispersion of water into the phase. This phenomenon may be a result of increased hydrate (hemiketal) formation at the elevated temperatures or simply kinetic dispersion of clusters into the organic phase. These explanations, however, are speculative in the absence of accurate LLE data and require further studies to understand this phenomenon. 


\section{Furfural production from birch hydrolysate}

The production of FUR from birch hydrolysate was studied under optimized conditions for the dehydration of $\mathrm{C}_{5}$ sugars $\left(190{ }^{\circ} \mathrm{C}, 1: 1\right.$ aqueous to $\mathrm{CPME}$ phase ratio, under microwave irradiation). The initial composition of the birch hydrolysate is provided in Table A1 (in the Supporting Information).

The FUR concentration increased from $84 \mathrm{mmol} \mathrm{I}^{-1}$ to $157 \mathrm{mmol} \mathrm{I}^{-1}$ with an increasing time from 30 to $120 \mathrm{~min}$ at $190{ }^{\circ} \mathrm{C}$ when employing an aqueous to CPME phase ratio of 1:1 (Figure 11a). In comparison to the auto-catalyzed system in monophase (Figure 11b), a lower concentration of FUR was obtained $\left(112 \mathrm{mmol} \mathrm{I}^{-1}\right)$. Furthermore, the conversion of xylose in both systems behave similarly, which confirms that the organic solvent plays no effect on the xylose dehydration process, but it protects formed FUR from further decomposition. Hydroxymehtylfurfural (HMF) highest concentration was $7 \mathrm{mmol} / \mathrm{L}$ (Figure A3 in the Supporting Information), which is in agreement with previous studies(Ershova, Nieminen and Sixta, 2017) when using birch hydrolysate to produce FUR from pentoses. 

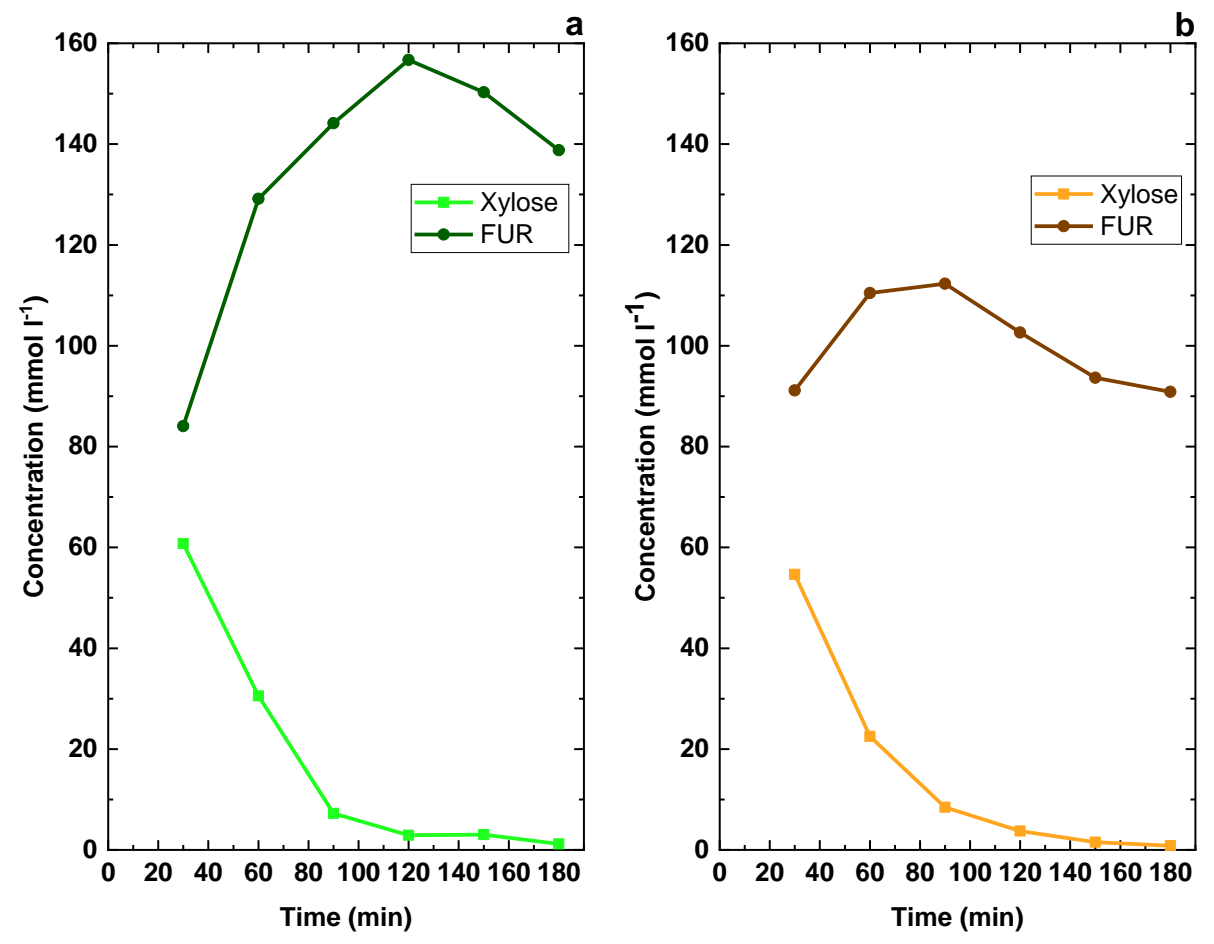

Figure 11. FUR and xylose concentrations from birch hydrolysate as a function of time at $190{ }^{\circ} \mathrm{C}$ under microwave irradiation. ${ }^{a}$ Reaction conditions: hydrolysate liquor after filtration (1.5 ml), CPME (1.5 ml). ${ }^{b}$ Reaction conditions: hydrolysate liquor after filtration $(3 \mathrm{ml})$. The lines are to guide the eye.

\section{Conclusion}

The on-site exctraction properties of three water-immiscible organic solvents in the xylose dehydration into FUR in a bi-phasic system was investigated under well-controlled conditions. The optimum aqueous-to-organic phase ratio for all three tested organic solvents was 1:1 to extract FUR in the dehydration of xylose. The major product of autocatalyzed and solid acid-catalyzed xylose dehydration was FUR, the maximum mole fraction yield of which was $78 \%$ in 180 min at $190{ }^{\circ} \mathrm{C}$ when using CPME. When adding this ether, the highest selectivity to FUR (93\%) was reached in 90 min at $170{ }^{\circ} \mathrm{C}$. 
The results related to the FUR production from birch hydrolysate show that the maximum concentration of FUR is $157 \mathrm{mmol}^{-1}$, based on the total pentoses (xylose and arabinose), is achieved after 120 min of hydrothermal reaction at $190^{\circ} \mathrm{C}$.

The results of the experiments when using isophorone as organic solvent allowed us to conclude that there are decomposition reactions between the solvent and FUR above $110^{\circ} \mathrm{C}$, which may or may not be linked to an increase on water solubility at elevated temperatures. Therefore, even though isophorone shows a higher partition coefficient in the biphasic system, it should be employed at temperatures below the conditions stated in the present study.

Studies concerning in-situ extraction of FUR involving water-immiscible solvents show a high selectivity to FUR, hence boosting its yield. This offers an interesting approach for a greener process and avoidance of salt addition.

\section{Acknowledgements}

This research has been done in collaboration with Stora Enso and funded through Erasmus Mundus Joint Doctoral Programme SELECT+, the support of which is gratefully acknowledged. GGM was supported also by CONACyT (the Mexican National Council of Science and Technology) through the doctoral fellowship No. 441618. The authors are also grateful for the support of the staff at the Department of Bioproducts and Biosystems at Aalto University especially to Heidi Meriö-Talvio and Mika Sipponen. JL is a Serra Húnter Fellow and is grateful to ICREA Academia program.

\section{References}

References 
14. Applications of furfural, 2000. Sugar Series. 13, 98-103.

Ahluwalia, V.K., Kidwai, M., 2004. Basic Principles of Green Chemistry, Ahluwalia, V.K., Kidwai, M. (Eds.), New Trends in Green Chemistry. Springer Netherlands, Dordrecht, pp. 5-14.

Alexandra, G., Thomas, L., Hedda, W., Walter, M., Herbert, S., 2006. Xylo-

- Oligosaccharide (XOS) Formation through Hydrothermolysis of Xylan Derived from Viscose Process, Macromol. Symp. 232, 107-120.

Argyle, D.M., Bartholomew, H.C., 2015. Heterogeneous Catalyst Deactivation and Regeneration: A Review, Catalysts. 5,.

Bruce, S.M., Zong, Z., Chatzidimitriou, A., Avci, L.E., Bond, J.Q., Carreon, M.A., Wettstein, S.G., 2016. Small pore zeolite catalysts for furfural synthesis from xylose and switchgrass in a $y$-valerolactone/water solvent, Journal of Molecular Catalysis A: Chemical. 422, 18-22.

Campos Molina, M.J., Mariscal, R., Ojeda, M., López Granados, M., 2012. Cyclopentyl methyl ether: A green co-solvent for the selective dehydration of lignocellulosic pentoses to furfural, Bioresour. Technol. 126, 321-327.

Chen, X., Zhang, L., Zhang, B., Guo, X., Mu, X., 2016. Highly selective hydrogenation of furfural to furfuryl alcohol over Pt nanoparticles supported on g-C3N4 nanosheets catalysts in water, Scientific Reports. 6, 28558.

Danon, B., Hongsiri, W., van der Aa, L., de Jong, W., 2014. Kinetic study on homogeneously catalyzed xylose dehydration to furfural in the presence of arabinose and glucose, Biomass Bioenergy. 66, 364-370.

Danon, B., van der Aa, L., de Jong, W., 2013. Furfural degradation in a dilute acidic and saline solution in the presence of glucose, Carbohydrate Research. 375, 145-152.

Dhepe, P.L., Sahu, R., 2010. A solid-acid-based process for the conversion of hemicellulose, Green Chem. 12, 2153-2156.

Dias, A.S., Lima, S., Pillinger, M., Valente, A.A., 2007. Modified versions of sulfated zirconia as catalysts for the conversion of xylose to furfural, Catalysis Letters. 114, 151160.

Dias, A.S., Lima, S., Pillinger, M., Valente, A.A., 2006. Acidic cesium salts of 12tungstophosphoric acid as catalysts for the dehydration of xylose into furfural, Carbohydrate Research. 341, 2946-2953.

Dias, A.S., Pillinger, M., Valente, A.A., 2005a. Dehydration of xylose into furfural over micro-mesoporous sulfonic acid catalysts, Journal of Catalysis. 229, 414-423. 
Dias, A.S., Pillinger, M., Valente, A.A., 2005b. Liquid phase dehydration of d-xylose in the presence of Keggin-type heteropolyacids, Applied Catalysis A: General. 285, 126131.

Dussan, K., Girisuta, B., Lopes, M., Leahy, J.J., Hayes, M.H.B., 2016. Effects of Soluble Lignin on the Formic Acid-Catalyzed Formation of Furfural: A Case Study for the Upgrading of Hemicellulose, ChemSusChem. 9, 492-504.

Ennaert, T., Van Aelst, J., Dijkmans, J., De Clercq, R., Schutyser, W., Dusselier, M., Verboekend, D., Sels, B.F., 2016. Potential and challenges of zeolite chemistry in the catalytic conversion of biomass, Chem. Soc. Rev. 45, 584-611.

Ershova, O., Nieminen, K., Sixta, H., 2017. The Role of Various Chlorides on Xylose Conversion to Furfural: Experiments and Kinetic Modeling, ChemCatChem. 9, 30313040.

Ershova, O., Pokki, J., Zaitseva, A., Alopaeus, V., Sixta, H., 2018. Vapor pressure, vapor-liquid equilibria, liquid-liquid equilibria and excess enthalpy of the system consisting of isophorone, furfural, acetic acid and water, Chemical Engineering Science. $176,19-34$.

Ferreira, L.R., Lima, S., Neves, P., Antunes, M.M., Rocha, S.M., Pillinger, M., Portugal, I., Valente, A.A., 2013. Aqueous phase reactions of pentoses in the presence of nanocrystalline zeolite beta: Identification of by-products and kinetic modelling, Chem. Eng. J. 215-216, 772-783.

Filiciotto, L., Balu, A.M., Van der Waal, J.C., Luque, R., 2017. Catalytic insights into the production of biomass-derived side products methyl levulinate, furfural and humins, Catalysis Today. In Press,.

Garg, B., Bisht, T., Ling, Y., 2014. Graphene-Based Nanomaterials as Heterogeneous Acid Catalysts: A Comprehensive Perspective, Molecules. 19,.

Givry, S., Bliard, C., Duchiron, F., 2007. Selective ketopentose analysis in concentrate carbohydrate syrups by HPLC, Carbohydr. Res. 342, 859-864.

Guenic, S.L., Delbecq, F., Ceballos, C., Len, C., 2015. Microwave-assisted dehydration of $D$-xylose into furfural by diluted inexpensive inorganic salts solution in a biphasic system, Journal of Molecular Catalysis A: Chemical. 410, 1-7.

Jing, Q., Lü, X., 2007. Kinetics of Non-catalyzed Decomposition of D-xylose in High Temperature Liquid Water, Chinese Journal of Chemical Engineering. 15, 666-669.

Kamm, B., Gruber, P.R., Kamm, M., 2010. Biorefineries - Industrial Processes and Products: Status Quo and Future Directions, Anonymous Wiley-VCH, pp. 949. 
Kim, S.B., You, S.J., Kim, Y.T., Lee, S., Lee, H., Park, K., Park, E.D., 2011. Dehydration of D-xylose into furfural over H-zeolites, Korean Journal of Chemical Engineering. 28, 710-716.

Konwar, L.J., Mäki-Arvela, P., Salminen, E., Kumar, N., Thakur, A.J., Mikkola, J., Deka, D., 2015. Towards carbon efficient biorefining: Multifunctional mesoporous solid acids obtained from biodiesel production wastes for biomass conversion, Applied Catalysis B: Environmental. 176-177, 20-35.

Lam, E., Chong, J.H., Majid, E., Liu, Y., Hrapovic, S., Leung, A.C.W., Luong, J.H.T., 2012. Carbocatalytic dehydration of xylose to furfural in water, Carbon. 50, 1033-1043.

Lam, E., Majid, E., Leung, A.C.W., Chong, J.H., Mahmoud, K.A., Luong, J.H.T., 2011. Synthesis of Furfural from Xylose by Heterogeneous and Reusable Nafion Catalysts, ChemSusChem. 4, 535-541.

Lamminpää, K., Ahola, J., Tanskanen, J., 2012. Kinetics of Xylose Dehydration into Furfural in Formic Acid, Ind Eng Chem Res. 51, 6297-6303.

Lamminpää, K., Ahola, J., Tanskanen, J., 2014. Kinetics of furfural destruction in a formic acid medium, RSC Adv. 4, 60243-60248.

Lessard, J., Morin, J., Wehrung, J., Magnin, D., Chornet, E., 2010. High Yield Conversion of Residual Pentoses into Furfural via Zeolite Catalysis and Catalytic Hydrogenation of Furfural to 2-Methylfuran, Topics in Catalysis. 53, 1231-1234.

Lima, S., Antunes, M.M., Fernandes, A., Pillinger, M., Ribeiro, M.F., Valente, A.A., 2010. Catalytic cyclodehydration of xylose to furfural in the presence of zeolite $\mathrm{H}$-Beta and a micro/mesoporous Beta/TUD-1 composite material, Applied Catalysis A: General. $388,141-148$.

Lima, S., Pillinger, M., Valente, A.A., 2008. Dehydration of D-xylose into furfural catalysed by solid acids derived from the layered zeolite Nu-6(1), Catalysis Communications. 9, 2144-2148.

Männistö, M., Pokki, J., Alopaeus, V., 2018. Quaternary and ternary LLE measurements for solvent (2-methyltetrahydrofuran and cyclopentyl methyl ether) + furfural + acetic acid + water between 298 and $343 \mathrm{~K}$, The Journal of Chemical Thermodynamics. 119, 61-75.

Männistö, M., Pokki, J., Fournis, L., Alopaeus, V., 2017. Ternary and binary LLE measurements for solvent (2-methyltetrahydrofuran and cyclopentyl methyl ether)+furfural+water between 298 and 343K, The Journal of Chemical Thermodynamics. 110, 127-136. 
Marcotullio, G., de Jong, W., Tavares Cardoso, M.A., Verkooijen, A.H.M., 2009. Bioenergy II: Furfural Destruction Kinetics during Sulphuric Acid-Catalyzed Production from Biomass, International Journal of Chemical Reactor Engineering. 7(1):A67,.

Mariscal, R., Maireles-Torres, P., Ojeda, M., Sadaba, I., Lopez Granados, M., 2016. Furfural: a renewable and versatile platform molecule for the synthesis of chemicals and fuels, Energy Environ. Sci. 9, 1144-1189.

Metkar, P.S., Till, E.J., Corbin, D.R., Pereira, C.J., Hutchenson, K.W., Sengupta, S.K., 2015. Reactive distillation process for the production of furfural using solid acid catalysts, Green Chem. 17, 1453-1466.

Mittal, A., Black, S.K., Vinzant, T.B., O'Brien, M., Tucker, M.P., Johnson, D.K., 2017. Production of Furfural from Process-relevant Biomass-derived Pentoses in a Biphasic Reaction System, ACS Sustainable Chem. Eng.

O'Neill, R., Ahmad, M.N., Vanoye, L., Aiouache, F., 2009. Kinetics of Aqueous Phase Dehydration of Xylose into Furfural Catalyzed by ZSM-5 Zeolite, Ind Eng Chem Res. 48, 4300-4306.

Pace, V., Holzer, W., Hoyos, P., Hernáiz, M.J., Alcántara, A.R., 2001. 2Methyltetrahydrofuran, Anonymous Encyclopedia of Reagents for Organic Synthesis. John Wiley \& Sons, Ltd, .

Paniagua, M., Saravanamurugan, S., Melian-Rodriguez, M., Melero, J.A., Riisager, A., 2015. Xylose Isomerization with Zeolites in a Two-Step Alcohol-Water Process, ChemSusChem. 8, 1088-1094.

Peleteiro, S., Rivas, S., Alonso, J.L., Santos, V., Parajó, J.C., 2016. Furfural production using ionic liquids: A review, Bioresource Technology. 202, 181-191.

Perez, R.F., Canhaci, S.J., Borges, L.E.P., Fraga, M.A., 2017. One-step conversion of xylose to furfuryl alcohol on sulfated zirconia-supported Pt catalyst-Balance between acid and metal sites, Catalysis Today. 289, 273-279.

Pirola, C., Rossetti, I., Ragaini, V., 2013. Are conversion, selectivity and yield terms unambiguously defined in chemical and chemical engineering technology? La Chimica \& L'Industria. 2, 136-145.

Rasmussen, H., Sørensen, H.R., Meyer, A.S., 2014. Formation of degradation compounds from lignocellulosic biomass in the biorefinery: sugar reaction mechanisms, Carbohydr. Res. 385, 45-57.

Sairanen, E., Vilonen, K., Karinen, R., Lehtonen, J., 2013. Functionalized Activated Carbon Catalysts in Xylose Dehydration, Topics in Catalysis. 56, 512-521. 
Sluiter, A., Hames, B., Ruiz, R., Scarlata, C., Sluiter, J., Templeton, D., 2008. Determination of Sugars, Byproducts, and Degradation Products in Liquid Fraction Process Samples, Technical Report NREL/TP-510-42623.

Suganuma, S., Nakajima, K., Kitano, M., Kato, H., Tamura, A., Kondo, H., Yanagawa, S., Hayashi, S., Hara, M., 2011. SO3H-bearing mesoporous carbon with highly selective catalysis, Microporous and Mesoporous Materials. 143, 443-450.

Tenne, S., Kinzel, J., Arlt, M., Sibilla, F., Bocola, M., Schwaneberg, U., 2013. 2Methyltetrahydrofuran and cyclopentylmethylether: Two green solvents for efficient purification of membrane proteins like FhuA, Journal of Chromatography B. 937, 13-17.

Tenne, S., Schwaneberg, U., 2012. First Insights on Organic Cosolvent Effects on FhuA Wildtype and FhuA Î"1-159, International Journal of Molecular Sciences. 13,.

Trimble, F., Dunlop, A.P., 1940. Recovery of Furfural from Aqueous Solutions, Ind. Eng. Chem. Anal. Ed. 12, 721-722.

van Zandvoort, I., Wang, Y., Rasrendra, C.B., van Eck, E.R.H., Bruijnincx, P.C.A., Heeres, H.J., Weckhuysen, B.M., 2013. Formation, Molecular Structure, and Morphology of Humins in Biomass Conversion: Influence of Feedstock and Processing Conditions, ChemSusChem. 6, 1745-1758.

Watanabe, K., 2013. The Toxicological Assessment of Cyclopentyl Methyl Ether (CPME) as a Green Solvent, Molecules. 18,.

Weingarten, R., Cho, J., Conner, J.,Wm.Curtis, Huber, G.W., 2010. Kinetics of furfural production by dehydration of xylose in a biphasic reactor with microwave heating, Green Chem. 12, 1423-1429.

Werpy, T., Petersen, G., 2004. Top Value Added Chemicals from Biomass: Volume I -Results of Screening for Potential Candidates from Sugars and Synthesis Gas; Sponsor Org.: US Department of Energy (US),.

Williams, D.L., Dunlop, A.P., 1948. Kinetics of Furfural Destruction in Acidic Aqueous Media, Ind. Eng. Chem. 40, 239-241.

Xue, F., Miao, C., Yue, Y., Hua, W., Gao, Z., 2017. Direct conversion of bio-ethanol to propylene in high yield over the composite of In2O3 and zeolite beta, Green Chem. 19, 5582-5590.

Yadav, G.D., Nair, J.J., 1999. Sulfated zirconia and its modified versions as promising catalysts for industrial processes, Microporous and Mesoporous Materials. 33, 1-48. 
Yang, L., Su, J., Carl, S., Lynam, J.G., Yang, X., Lin, H., 2015. Catalytic conversion of hemicellulosic biomass to lactic acid in $\mathrm{pH}$ neutral aqueous phase media, Applied Catalysis B: Environmental. 162, 149-157.

You, S.J., Kim, Y.T., Park, E.D., 2014. Liquid-phase dehydration of d-xylose over silicaalumina catalysts with different alumina contents, Reaction Kinetics, Mechanisms and Catalysis. 111, 521-534.

Zhang, J., Zhuang, J., Lin, L., Liu, S., Zhang, Z., 2012. Conversion of D-xylose into furfural with mesoporous molecular sieve MCM-41 as catalyst and butanol as the extraction phase, Biomass and Bioenergy. 39, 73-77. 